\title{
Consensus Statement on Concussion in Sport - the 3rd International Conference on Concussion in Sport held in Zurich, November 2008
}

\author{
P McCrory, W Meeuwisse, K Johnston, J Dvorak, M Aubry, M Molloy, R Cantu \\ Consensus panellists (listed in alphabetical order): In addition to the authors above, the consensus panellists were Broglio $S$, Davis $\mathrm{G}$, \\ Dick R, Dvorak J, Echemendia R, Gioia G, Guskiewicz K, Herring S, Iverson G, Kelly J, Kissick J, Makdissi M, McCrea M, Ptito A, Purcell L, \\ Putukian M. Also invited but not in attendance: Bahr R, Engebretsen L, Hamlyn P, Jordan B, Schamasch P
}

\begin{abstract}
Author affiliations
P McCrory - Neurologist. Director, Centre for Health, Exercise \& Sports Medicine, University of Melbourne, Parkville, Australia 3010

Willem Meeuwisse - Sports Physician, Sport Medicine Centre, Faculty of Kinesiology, and Department of Community Health Sciences, Faculty of Medicine, University of Calgary, 2500 University Drive N.W., Calgary, Alberta, Canada, T2N 1N4

Karen Johnston - Neurosurgeon and Director, Sport Concussion Clinic, Toronto Rehabilitation Institute, 550 University Avenue, Toronto, ON, M5G 2A2 Canada

Jiri Dvorak - Neurologist. Director, FIFA Medical Assessment and Research Center (F-MARC) and Schulthess Clinic, Zurich, Switzerland

Mark Aubry - Chief Medical Officer, International Ice Hockey Federation and Hockey Canada, Co-Director Ottawa Sport Medicine Centre, 1370 Clyde Avenue, Ottawa, Canada, K1T 3Y8

Mick Molloy - Chief Medical Officer, International Rugby Board, Huguenot House, 35-38 St Stephen's Green, Dublin 2, Ireland

Robert Cantu - Neurosurgeon, 131 ORNAC, Suite 820, John Cuming Building, Emerson Hospital, Concord, MA 01742 USA
\end{abstract}

\section{Preamble}

This paper is a revision and update of the recommendations developed following the 1st (Vienna) and 2nd (Prague) International Sym-

\section{CORRESPONDENCE}

A/Prof Paul McCrory

Centre for Health, Exercise \& Sports Medicine

University of Melbourne, Parkville, Australia 3010

Tel: $\quad+61383444135$

Fax: $\quad+61383443771$

E-mail: paulmccr@bigpond.net.au

Competing interests: The authors have no competing interests to declare.

This is a co-publication. See editorial on p.34 for details. posia on Concussion in Sport. $(1,2)$ The Zurich Consensus statement is designed to build on the principles outlined in the original Vienna and Prague documents and to develop further conceptual understanding of this problem using a formal consensus-based approach. A detailed description of the consensus process is outlined at the end of this document under the "background" section (See Section 11). This document is developed for use by physicians, therapists, certified athletic trainers, health professionals, coaches and other people involved in the care of injured athletes, whether at the recreational, elite or professional level.

While agreement exists pertaining to principal messages conveyed within this document, the authors acknowledge that the science of concussion is evolving and therefore management and return to play decisions remain in the realm of clinical judgment on an individualized basis. Readers are encouraged to copy and distribute freely the Zurich Consensus document and/or the Sports Concussion Assessment Tool (SCAT2) card and neither is subject to any copyright restriction. The authors request, however that the document and/or the SCAT2 card be distributed in their full and complete format.

The following focus questions formed the foundation for the Zurich concussion consensus statement:

\section{Acute simple concussion}

- Which symptom scale \& which sideline assessment tool is best for diagnosis and/or follow up?

- How extensive should the cognitive assessment be in elite athletes?

- How extensive should clinical and neuropsychological (NP) testing be at non-elite level?

-Who should do/interpret the cognitive assessment?

- Is there a gender difference in concussion incidence and outcomes?

\section{Return to play (RTP) issues}

- Is provocative exercise testing useful in guiding RTP?

- What is the best RTP strategy for elite athletes?

- What is the best RTP strategy for non-elite athletes?

- Is protective equipment (e.g. mouthguards and helmets) useful in reducing concussion incidence and/or severity?

\section{Complex concussion and long term issues}

- Is the Simple versus Complex classification a valid and useful differentiation? 
- Are there specific patient populations at risk of long-term problems?

- Is there a role for additional tests (e.g. structural and/or functional MR Imaging, balance testing, biomarkers)?

- Should athletes with persistent symptoms be screened for depression/anxiety?

\section{Paediatric concussion}

-Which symptoms scale is appropriate for this age group?

- Which tests are useful and how often should baseline testing be performed in this age group?

- What is the most appropriate RTP guideline for elite and non-elite child and adolescent athlete?

\section{Future directions}

-What is the best method of knowledge transfer and education

- Is there evidence that new and novel injury prevention strategies work (e.g. changes to rules of the game, fair play strategies etc)?

The Zurich document additionally examines the management issues raised in the previous Prague and Vienna documents and applies the consensus questions to these areas.

\section{SPECIFIC RESEARCH QUESTIONS AND CONSEN- SUS DISCUSSION}

\section{1) CONCUSSION}

\subsection{Definition of Concussion}

Panel discussion regarding the definition of concussion and its separation from mild traumatic brain injury (mTBI) was held. Although there was acknowledgement that the terms refer to different injury constructs and should not be used interchangeably, it was not felt that the panel would define mTBI for the purpose of this document. There was unanimous agreement however that concussion is defined as follows:

Concussion is defined as a complex pathophysiological process affecting the brain, induced by traumatic biomechanical forces. Several common features that incorporate clinical, pathologic and biomechanical injury constructs that may be utilized in defining the nature of a concussive head injury include:

1. Concussion may be caused either by a direct blow to the head, face, neck or elsewhere on the body with an "impulsive" force transmitted to the head.

2. Concussion typically results in the rapid onset of shortlived impairment of neurologic function that resolves spontaneously.

3. Concussion may result in neuropathological changes but the acute clinical symptoms largely reflect a functional disturbance rather than a structural injury.

4. Concussion results in a graded set of clinical symptoms that may or may not involve loss of consciousness. Resolution of the clinical and cognitive symptoms typically follows a sequential course however it is important to note that in a small percentage of cases however, post-concussive symptoms may be prolonged.

5. No abnormality on standard structural neuroimaging studies is seen in concussion.

\subsection{Classification of Concussion}

There was unanimous agreement to abandon the simple vs. complex terminology that had been proposed in the Prague agreement statement as the panel felt that the terminology itself did not fully describe the entities. The panel however unanimously retained the concept that the majority (80-90\%) of concussions resolve in a short (7-10 day) period, although the recovery time frame may be longer in children and adolescents.(2)

\section{2) CONCUSSION EVALUATION}

\subsection{Symptoms and signs of acute concussion}

The panel agreed that the diagnosis of acute concussion usually involves the assessment of a range of domains including clinical symptoms, physical signs, behavior, balance, sleep and cognition. Furthermore, a detailed concussion history is an important part of the evaluation both in the injured athlete and when conducting a preparticipation examination. The detailed clinical assessment of concussion is outlined in the SCAT2 form, which is an appendix to this document.

The suspected diagnosis of concussion can include one or more of the following clinical domains:

(a) Symptoms - somatic (e.g. headache), cognitive (e.g. feeling like in a fog) and/or emotional symptoms (e.g. lability)

(b) Physical signs (e.g. loss of consciousness, amnesia)

(c) Behavioural changes (e.g. irritablity)

(d) Cognitive impairment (e.g. slowed reaction times)

(e) Sleep disturbance (e.g. drowsiness)

If any one or more of these components is present, a concussion should be suspected and the appropriate management strategy instituted.

\subsection{On-field or sideline evaluation of acute concussion}

When a player shows ANY features of a concussion:

(a) The player should be medically evaluated onsite using standard emergency management principles and particular attention should be given to excluding a cervical spine injury.

(b) The appropriate disposition of the player must be determined by the treating healthcare provider in a timely manner. If no healthcare provider is available, the player should be safely removed from practice or play and urgent referral to a physician arranged.

(c) Once the first aid issues are addressed, then an assessment of the concussive injury should be made using the SCAT2 or other similar tool.

(d) The player should not be left alone following the injury and serial monitoring for deterioration is essential over the initial few hours following injury.

(e) A player with diagnosed concussion should not be allowed to return to play on the day of injury. Occasionally in adult athletes, there may be return to play on the same day as the injury. See section 4.2

It was unanimously agreed that sufficient time for assessment and adequate facilities should be provided for the appropriate medical assessment both on and off the field for all injured athletes. In some sports this may require rule change to allow an off-field medical assessment to occur without affecting the flow of the game or unduly penalizing the injured player's team. 
Sideline evaluation of cognitive function is an essential component in the assessment of this injury. Brief neuropsychological test batteries that assess attention and memory function have been shown to be practical and effective. Such tests include the Maddocks questions $(3,4)$ and the Standardized Assessment of Concussion (SAC). (5-7) It is worth noting that standard orientation questions (e.g. time, place, person) have been shown to be unreliable in the sporting situation when compared with memory assessment. $(4,8)$ It is recognized, however, that abbreviated testing paradigms are designed for rapid concussion screening on the sidelines and are not meant to replace comprehensive neuropsychological testing which is sensitive to detect subtle deficits that may exist beyond the acute episode; nor should they be used as a stand-alone tool for the ongoing management of sports concussions.

It should also be recognized that the appearance of symptoms might be delayed several hours following a concussive episode.

\subsection{Evaluation in emergency room or office by medical person-} nel

An athlete with concussion may be evaluated in the emergency room or doctor's office as a point of first contact following injury or may have been referred from another care provider. In addition to the points outlined above, the key features of this exam should encompass:

(a) A medical assessment including a comprehensive history and detailed neurological examination including a thorough assessment of mental status, cognitive functioning and gait and balance.

(b) A determination of the clinical status of the patient including whether there has been improvement or deterioration since the time of injury. This may involve seeking additional information from parents, coaches, teammates and eyewitness to the injury.

(c) A determination of the need for emergent neuroimaging in order to exclude a more severe brain injury involving a structural abnormality

In large part, these points above are included in the SCAT2 assessment, which forms part of the Zurich consensus statement.

\section{3) CONCUSSION INVESTIGATIONS}

A range of additional investigations may be utilized to assist in the diagnosis and/or exclusion of injury. These include:

\subsection{Neuroimaging}

It was recognized by the panelists that conventional structural neuroimaging is normal in concussive injury. Given that caveat, the following suggestions are made: Brain CT (or where available MR brain scan) contributes little to concussion evaluation but should be employed whenever suspicion of an intra-cerebral structural lesion exists. Examples of such situations may include prolonged disturbance of conscious state, focal neurological deficit or worsening symptoms.

Newer structural MRI modalities including gradient echo, perfusion and diffusion imaging have greater sensitivity for structural abnormalities. However, the lack of published studies as well as absent pre-injury neuroimaging data limits the usefulness of this approach in clinical management at the present time. In addition, the predictive value of various MR abnormalities that may be incidentally discovered is not established at the present time.
Other imaging modalities such as fMRI demonstrate activation patterns that correlate with symptom severity and recovery in concussion. (9-13) Whilst not part of routine assessment at the present time, they nevertheless provide additional insight to pathophysiological mechanisms. Alternative imaging technologies (e.g. positron emission tomography, diffusion tensor imaging, magnetic resonance spectroscopy, functional connectivity), while demonstrating some compelling $\square$ ndings, are still at early stages of development and cannot be recommended other than in a research setting.

\subsection{Objective Balance Assessment}

Published studies, using both sophisticated force plate technology, as well as those using less sophisticated clinical balance tests (e.g. Balance Error Scoring System (BESS)), have identified postural stability deficits lasting approximately 72 hours following sport-related concussion. It appears that postural stability testing provides a useful tool for objectively assessing the motor domain of neurologic functioning, and should be considered a reliable and valid addition to the assessment of athletes suffering from concussion, particularly where symptoms or signs indicate a balance component. (14-20)

\subsection{Neuropsychological Assessment}

The application of neuropsychological (NP) testing in concussion has been shown to be of clinical value and continues to contribute significant information in concussion evaluation. (21-26) Although in most case cognitive recovery largely overlaps with the time course of symptom recovery, it has been demonstrated that cognitive recovery may occasionally precede or more commonly follow clinical symptom resolution suggesting that the assessment of cognitive function should be an important component in any return to play protocol. (27, 28) It must be emphasized however, that NP assessment should not be the sole basis of management decisions rather it should be seen as an aid to the clinical decision-making process in conjunction with a range of clinical domains and investigational results.

Neuropsychologists are in the best position to interpret NP tests by virtue of their background and training. However, there may be situations where neuropsychologists are not available and other medical professionals may perform or interpret NP screening tests. The ultimate return to play decision should remain a medical one in which a multidisciplinary approach, when possible, has been taken. In the absence of NP and other (e.g. formal balance assessment) testing, a more conservative return to play approach may be appropriate.

In the majority of cases, NP testing will be used to assist return to play decisions and will not be done until patient is symptom free. $(29,30)$ There may be situations (e.g. child and adolescent athletes) where testing may be performed early whilst the patient is still symptomatic to assist in determining management. This will normally be best determined in consultation with a trained neuropsychologist. $(31,32)$

\subsection{Genetic Testing}

The significance of Apolipoprotein (Apo) E4, ApoE promotor gene, Tau polymerase and other genetic markers in the management of sports concussion risk or injury outcome is unclear at this time. (33, 34) Evidence from human and animal studies in more severe traumatic brain injury demonstrate induction of a variety of genetic and cytokine factors such as: insulin-like growth factor-1 (IGF-1), IGF binding protein-2, Fibroblast growth factor, $\mathrm{Cu}-\mathrm{Zn}$ superoxide dismutase, superoxide dismutase -1 (SOD-1), nerve growth factor, glial fibrillary acidic protein (GFAP) and S-100. Whether such factors are affected in sporting concussion is not known at this stage. (35-42) 


\subsection{Experimental Concussion Assessment Modalities}

Different electrophysiological recording techniques (e.g. evoked response potential (ERP), cortical magnetic stimulation and electroencephalography) have demonstrated reproducible abnormalities in the post concussive state, however not all studies reliably differentiated concussed athletes from controls. (43-49) The clinical significance of these changes remains to be established.

In addition, biochemical serum and cerebral spinal fluid markers of brain injury (including S-100, neuron specific enolase (NSE), myelin basic protein (MBP), GFAP, tau etc) have been proposed as means by which cellular damage may be detected if present. (50-56) There is currently insufficient evidence however, to justify the routine use of these biomarkers clinically.

\section{4) CONCUSSION MANAGEMENT}

The cornerstone of concussion management is physical and cognitive rest until symptoms resolve and then a graded program of exertion prior to medical clearance and return to play. The recovery and outcome of this injury may be modified by a number of factors that may require more sophisticated management strategies. These are outlined in the section on modifiers below.

As described above, the majority of injuries will recover spontaneously over several days. In these situations, it is expected that an athlete will proceed progressively through a stepwise return to play strategy. (57) During this period of recovery while symptomatic following an injury, it is important to emphasize to the athlete that physical AND cognitive rest is required. Activities that require concentration and attention (e.g. scholastic work, videogames, text messaging etc) may exacerbate symptoms and possibly delay recovery. In such cases, apart from limiting relevant physical and cognitive activities (and other risk-taking opportunities for re-injury) while symptomatic, no further intervention is required during the period of recovery and the athlete typically resumes sport without further problem.

\subsection{Graduated Return to Play Protocol}

Return to play protocol following a concussion follows a stepwise process as outlined in Table 1.

With this stepwise progression, the athlete should continue to proceed to the next level if asymptomatic at the current level. Generally each step should take 24 hours so that an athlete would take approximately one week to proceed through the full rehabilitation protocol once they are asymptomatic at rest and with provocative exercise. If any post concussion symptoms occur while in the stepwise program then the patient should drop back to the previous asymptomatic level and try to progress again after a further 24-hour period of rest has passed.

\subsection{Same day RTP}

With adult athletes, in some settings, where there are team physicians experienced in concussion management and sufficient resources (e.g. access to neuropsychologists, consultants, neuroimaging etc) as well as access to immediate (i.e. sideline) neuro-cognitive assessment, return to play management is may be more rapid. The RTP strategy must still follow the same basic management principles namely, full clinical and cognitive recovery before consideration of return to play. This approach is supported by published guidelines, such as the American Academy of Neurology, US Team Physician Consensus Statement, and US National Athletic Trainers Association Position Statement. (58-60) This issue was extensively discussed by the consensus panelists and it was acknowledged that there is evidence that some professional American football players

\begin{tabular}{|c|c|c|}
\hline $\begin{array}{l}\text { Rehabilitation } \\
\text { stage }\end{array}$ & $\begin{array}{l}\text { Functional exercise at each } \\
\text { stage of rehabilitation }\end{array}$ & $\begin{array}{l}\text { Objective } \\
\text { of each stage }\end{array}$ \\
\hline 1. No activity & $\begin{array}{l}\text { Complete physical } \\
\text { and cognitive rest. }\end{array}$ & Recovery \\
\hline $\begin{array}{l}\text { 2.Light aerobic } \\
\text { exercise }\end{array}$ & $\begin{array}{l}\text { Walking, swimming or } \\
\text { stationary cycling } \\
\text { keeping intensity } \\
<70 \% \text { MPHR } \\
\text { No resistance training. }\end{array}$ & Increase HR \\
\hline $\begin{array}{l}\text { 3.Sport-specific } \\
\text { exercise }\end{array}$ & $\begin{array}{l}\text { Skating drills in ice hockey, } \\
\text { running drills in soccer. } \\
\text { No head impact activities. }\end{array}$ & Add movement \\
\hline $\begin{array}{l}\text { 4.Non-contact } \\
\text { training drills }\end{array}$ & $\begin{array}{l}\text { Progression to more } \\
\text { complex training drills e,g. } \\
\text { passing drills in football and } \\
\text { ice hockey. May start load } \\
\text { progressive resistance training) }\end{array}$ & $\begin{array}{l}\text { Exercise, } \\
\text { coordination, } \\
\text { and cognitive } \\
\text { Restore }\end{array}$ \\
\hline $\begin{array}{l}\text { 5.Full contact } \\
\text { practice }\end{array}$ & $\begin{array}{l}\text { Following medical clearance } \\
\text { participate in normal training } \\
\text { activities }\end{array}$ & $\begin{array}{l}\text { confidence and } \\
\text { assess } \\
\text { functional skills } \\
\text { by coaching } \\
\text { staff }\end{array}$ \\
\hline 6. Return to play & Normal game play & \\
\hline
\end{tabular}

are able to RTP more quickly, with even same day RTP supported by NFL studies without a risk of recurrence or sequelae. (61) There is data however, demonstrating that at the collegiate and high school level, athletes allowed to RTP on the same day may demonstrate NP deficits post-injury that may not be evident on the sidelines and are more likely to have delayed onset of symptoms. (62-68) It should be emphasised however, the young $(<18)$ elite athlete should be treated more conservatively even though the resources may be the same as an older professional athlete. (See section 6.1)

\subsection{Psychological management and mental health issues}

In addition, psychological approaches may have potential application in this injury, particularly with the modifiers listed below. $(69,70)$ Care givers are also encouraged to evaluate the concussed athlete for affective symptoms such as depression as these symptoms may be common in concussed athletes.(57)

\subsection{The Role of Pharmacological Therapy}

Pharmacological therapy in sports concussion may be applied in two distinct situations. The first of these situations is the management of specific prolonged symptoms (e.g. sleep disturbance, anxiety etc.). The second situation is where drug therapy is used to modify the underlying pathophysiology of the condition with the aim of shortening the duration of the concussion symptoms.(71) In broad terms, this approach to management should be only considered by clinicians experienced in concussion management.

An important consideration in RTP is that concussed athletes should not only be symptom free but also should not be taking any pharmacological agents/medications that may mask or modify the symptoms of concussion. Where antidepressant therapy may be commenced during the management of a concussion, the decision to return to play while still on such medication must be considered carefully by the treating clinician.

\subsection{The role of pre-participation concussion evaluation}

Recognizing the importance of a concussion history, and appreciating the fact that many athletes will not recognize all the concussions they may have suffered in the past, a detailed concussion history is 
of value. (72-75) Such a history may pre-identify athletes that It into a high risk category and provides an opportunity for the healthcare provider to educate the athlete in regard to the significance of concussive injury. A structured concussion history should include specific questions as to previous symptoms of a concussion; not just the perceived number of past concussions. It is also worth noting that dependence upon the recall of concussive injuries by teammates or coaches has been demonstrated to be unreliable. (72) The clinical history should also include information about all previous head, face or cervical spine injuries as these may also have clinical relevance. It is worth emphasizing that in the setting of maxillofacial and cervical spine injuries, co- existent concussive injuries may be missed unless specifically assessed. Questions pertaining to disproportionate impact versus symptom severity matching may alert the clinician to a progressively increasing vulnerability to injury. As part of the clinical history it is advised that details regarding protective equipment employed at time of injury be sought, both for recent and remote injuries. The benefit a comprehensive pre-participation concussion evaluation allows for modification and optimization of protective behavior and an opportunity for education.

\section{5) MODIFYING FACTORS IN CONCUSSION MANAGEMENT}

The consensus panel agreed that a range of 'modifying' factors may influence the investigation and management of concussion and in some cases, may predict the potential for prolonged or persistent symptoms. These modifiers would also be important to consider in a detailed concussion history and are outlined in Table 2.

In this setting, there may be additional management considerations beyond simple RTP advice. There may be a more important role for additional investigations including: formal NP testing, balance assessment, and neuroimaging. It is envisioned that athletes with such modifying features would be managed in a multidisciplinary manner coordinated by a physician with specific expertise in the management of concussive injury.

The role of female gender as a possible modifier in the management of concussion was discussed at length by the panel.

\begin{tabular}{|c|c|}
\hline Factors & Modifier \\
\hline \multirow[t]{2}{*}{ Symptoms } & Number \\
\hline & $\begin{array}{l}\text { Duration (> } 10 \text { days) } \\
\text { Severity }\end{array}$ \\
\hline Signs & Prolonged LOC (> 1min), Amnesia \\
\hline Sequelae & Concussive convulsions \\
\hline Temporal & $\begin{array}{l}\text { Frequency - repeated concussions over time } \\
\text { Timing - injuries close together in time } \\
\text { "Recency" - recent concussion or TBI }\end{array}$ \\
\hline Threshold & $\begin{array}{l}\text { Repeated concussions occurring with } \\
\text { progressively less impact force or slower } \\
\text { recovery after each successive concussion. }\end{array}$ \\
\hline Age & Child and adolescent $(<18$ years old $)$ \\
\hline $\begin{array}{l}\text { Co and Pre- } \\
\text { morbidities }\end{array}$ & $\begin{array}{l}\text { Migraine, depression or other mental health } \\
\text { disorders, attention deficit hyperactivity } \\
\text { disorder (ADHD), learning disabilities (LD), } \\
\text { sleep disorders }\end{array}$ \\
\hline Medication & Psychoactive drugs, anticoagulants \\
\hline Behaviour & Dangerous style of play \\
\hline Sport & $\begin{array}{l}\text { High risk activity, contact and collision } \\
\text { sport, high sporting level }\end{array}$ \\
\hline
\end{tabular}

There was not unanimous agreement that the current published research evidence is conclusive that this should be included as a modifying factor although it was accepted that gender may be a risk factor for injury and/or influence injury severity. (76-78)

\subsection{The Significance of Loss of Consciousness (LOC)}

In the overall management of moderate to severe traumatic brain injury, duration of LOC is an acknowledged predictor of outcome. (79) Whilst published findings in concussion describe LOC associated with specific early cognitive deficits it has not been noted as a measure of injury severity. $(80,81)$ Consensus discussion determined that prolonged ( $>1$ minute duration) LOC would be considered as a factor that may modify management.

\subsection{The Significance of Amnesia and other symptoms}

There is renewed interest in the role of post-traumatic amnesia and its role as a surrogate measure of injury severity. $(67,82,83)$ Published evidence suggests that the nature, burden and duration of the clinical post-concussive symptoms may be more important than the presence or duration of amnesia alone. $(80,84,85)$ Further it must be noted that retrograde amnesia varies with the time of measurement post-injury and hence is poorly reflective of injury severity.(86, 87)

\subsection{Motor and convulsive phenomena}

A variety of immediate motor phenomena (e.g. tonic posturing) or convulsive movements may accompany a concussion. Although dramatic, these clinical features are generally benign and require no specific management beyond the standard treatment of the underlying concussive injury. $(88,89)$

\subsection{Depression}

Mental health issues (such as depression) have been reported as a long-term consequence of traumatic brain injury including sports related concussion. Neuroimaging studies using fMRI suggest that a depressed mood following concussion may reflect an underlying pathophysiological abnormality consistent with a limbic-frontal model of depression. (52, 90-100)

\section{6) SPECIAL POPULATIONS}

\subsection{The child and adolescent athlete}

There was unanimous agreement by the panel that the evaluation and management recommendations contained herein could be applied to children and adolescents down to the age of 10 years. Below that age children report different concussion symptoms different from adults and would require age appropriate symptom checklists as a component of assessment. An additional consideration in assessing the child or adolescent athlete with a concussion is that in the clinical evaluation by the healthcare professional there may be the need to include both patient and parent input as well as teacher and school input when appropriate. (101-107)

The decision to use NP testing is broadly the same as the adult assessment paradigm. However, timing of testing may differ in order to assist planning in school and home management (and may be performed while the patient is still symptomatic). If cognitive testing is performed then it must be developmentally sensitive until late teen years due to the ongoing cognitive maturation that occurs during this period which, in turn, makes the utility of comparison to either the person's own baseline performance or to population norms limited. (20) In this age group it is more important to consider the use of trained neuropsychologists to interpret assessment data, particularly in children with learning disorders and/or ADHD who may need more sophisticated assessment strategies. $(31,32,101)$ 
The panel strongly endorsed the view that children should not be returned to practice or play until clinically completely symptom free, which may require a longer time frame than for adults. In addition, the concept of 'cognitive rest' was highlighted with special reference to a child's need to limit exertion with activities of daily living and to limit scholastic and other cognitive stressors (e.g text messaging, videogames etc) while symptomatic. School attendance and activities may also need to be modified to avoid provocation of symptoms.

Because of the different physiological response \& longer recovery after concussion and specific risks (e.g. diffuse cerebral swelling) related to head impact during childhood and adolescence, a more conservative return to play approach is recommended. It is appropriate to extend the amount of time of asymptomatic rest and/ or the length of the graded exertion in children and adolescents. It is not appropriate for a child or adolescent athlete with concussion to RTP on the same day as the injury regardless of the level of athletic performance. Concussion modifiers apply even more to this population than adults and may mandate more cautious RTP advice.

\subsection{Elite vs Non-Elite Athletes}

The panel unanimously agreed that all athletes regardless of level of participation should be managed using the same treatment and return to play paradigm. A more useful construct was agreed whereby the available resources and expertise in concussion evaluation were of more importance in determining management than a separation between elite and non-elite athlete management. Although formal baseline NP screening may be beyond the resources of many sports or individuals, it is recommended that in all organized high risk sports consideration be given to having this cognitive evaluation regardless of the age or level of performance.

\subsection{Chronic Traumatic Brain Injury}

Epidemiological studies have suggested an association between repeated sports concussions during a career and late life cognitive impairment. Similarly, case reports have noted anecdotal cases where neuro-pathological evidence of chronic traumatic encephalopathy was observed in retired football players. (108-112) Panel discussion was held and no consensus was reached on the significance of such observations at this stage. Clinicians need to be mindful of the potential for long-term problems in the management of all athletes.

\section{7) INJURY PREVENTION}

\subsection{Protective equipment - mouthguards and helmets}

There is no good clinical evidence that currently available protective equipment will prevent concussion although mouthguards have a definite role in preventing dental and oro-facial injury. Biomechanical studies have shown a reduction in impact forces to the brain with the use of head gear and helmets, but these findings have not been translated to show a reduction in concussion incidence. For skiing and snowboarding there are a number of studies to suggest that helmets provide protection against head and facial injury and hence should be recommended for participants in alpine sports. (113-116) In specific sports such as cycling, motor and equestrian sports, protective helmets may prevent other forms of head injury (e.g. skull fracture) that are related to falling on hard road surfaces and these may be an important injury prevention issue for those sports. (116128)

\subsection{Rule change}

Consideration of rule changes to reduce the head injury incidence or severity may be appropriate where a clear-cut mechanism is impli- cated in a particular sport. An example of this is in football (soccer) where research studies demonstrated that upper limb to head contact in heading contests accounted for approximately $50 \%$ of concussions. (129). As noted earlier, rule changes also may be needed in some sports to allow an effective off-field medical assessment to occur without compromising the athlete's welfare, affecting the flow of the game or unduly penalizing the player's team. It is important to note that rule enforcement may be a critical aspect of modifying injury risk in these settings and referees play an important role in this regard.

\subsection{Risk compensation}

An important consideration in the use of protective equipment is the concept of risk compensation. (130) This is where the use of protective equipment results in behavioral change such as the adoption of more dangerous playing techniques, which can result in a paradoxical increase in injury rates. This may be a particular concern in child and adolescent athletes where head injury rates are often higher than in adult athletes. (131-133)

\subsection{Aggression versus violence in sport}

The competitive/aggressive nature of sport which makes it fun to play and watch should not be discouraged. However, sporting organizations should be encouraged to address violence that may increase concussion risk. $(134,135)$ Fair play and respect should be supported as key elements of sport.

\section{8) KNOWLEDGE TRANSFER}

As the ability to treat or reduce the effects of concussive injury after the event is minimal, education of athletes, colleagues and the general public is a mainstay of progress in this field. Athletes, referees, administrators, parents, coaches and health care providers must be educated regarding the detection of concussion, its clinical features, assessment techniques and principles of safe return to play. Methods to improve education including web-based resources, educational videos and international outreach programs are important in delivering the message. In addition, concussion working groups plus the support and endorsement of enlightened sport groups such as Fédération Internationale de Football Association (FIFA), International Olympic Commission (IOC), International Rugby Board (IRB) and International Ice Hockey Federation (IIHF) who initiated this endeavor have enormous value and must be pursued vigorously. Fair play and respect for opponents are ethical values that should be encouraged in all sports and sporting associations. Similarly coaches, parents and managers play an important part in ensuring these values are implemented on the field of play. $(57,136-148)$

\section{9) FUTURE DIRECTIONS}

The consensus panelists recognize that research is needed across a range of areas in order to answer some critical research questions. The key areas for research identified include:

\section{- Validation of the SCAT2}

- Gender effects on injury risk, severity and outcome

- Paediatric injury and management paradigms

- Virtual reality tools in the assessment of injury

- Rehabilitation strategies (e.g. exercise therapy)

- Novel Imaging modalities and their role in clinical assessment

- Concussion surveillance using consistent definitions and outcome measures

- Clinical assessment where no baseline assessment has been performed 
- 'Best-practice' neuropsychological testing

- Long term outcomes

- On-field injury severity predictors

\section{0) MEDICAL LEGAL CONSIDERATIONS}

This consensus document reflects the current state of knowledge and will need to be modified according to the development of new knowledge. It provides an overview of issues that may be of importance to healthcare providers involved in the management of sports related concussion. It is not intended as a standard of care, and should not be interpreted as such. This document is only a guide, and is of a general nature, consistent with the reasonable practice of a healthcare professional. Individual treatment will depend on the facts and circumstances specific to each individual case.

It is intended that this document will be formally reviewed and updated prior to 1 December 2012.

\section{1) STATEMENT ON BACKGROUND TO CONSENSUS PROCESS}

In November 2001, the 1st International Conference on Concussion in Sport was held in Vienna, Austria. This meeting was organized by the IIHF in partnership with FIFA and the Medical Commission of the IOC. As part of the resulting mandate for the future, the need for leadership and future updates were identi $\square$ ed. The 2 nd International Conference on Concussion in Sport was organized by the same group with the additional involvement of the IRB and was held in Prague, Czech Republic in November 2004. The original aims of the symposia were to provide recommendations for the improvement of safety and health of athletes who suffer concussive injuries in ice hockey, rugby, football (soccer) as well as other sports. To this end, a range of experts were invited to both meetings to address speci $\square \mathrm{c}$ issues of epidemiology, basic and clinical science, injury grading systems, cognitive assessment, new research methods, protective equipment, management, prevention and long term outcome. $(1,2)$

The 3rd International Conference on Concussion in Sport was held in Zurich, Switzerland on 29/30 October 2008 and was designed as a formal consensus meeting following the organizational guidelines set forth by the US National Institutes of Health. (Details of the consensus methodology can be obtained at: http://consensus.nih. gov/ABOUTCDP.htm) The basic principles governing the conduct of a consensus development conference are summarized below:

1. A broad based non-government, non-advocacy panel was assembled to give balanced, objective and knowledgeable attention to the topic. Panel members excluded anyone with scientific or commercial conflicts of interest and included researchers in clinical medicine, sports medicine, neuroscience, neuroimaging, athletic training and sports science.

2. These experts presented data in a public session, followed by inquiry and discussion. The panel then met in an executive session to prepare the consensus statement.

3. A number of specific questions were prepared and posed in advance to define the scope and guide the direction of the conference. The principle task of the panel was to elucidate responses to these questions. These questions are outlined below.

4. A systematic literature review was prepared and circulated in advance for use by the panel in addressing the conference questions.

5. The consensus statement is intended to serve as the scientific record of the conference.
6. The consensus statement will be widely disseminated to achieve maximum impact on both current health care practice and future medical research.

The panel chairperson (WM) did not identify with any advocacy position. The chairperson was responsible for directing the consensus session and guiding the panel's deliberations. Panelists were drawn from clinical practice, academic and research in the field of sports related concussion. They do not represent organisations per se but were selected for their expertise, experience and understanding of this field.

\section{References}

1. Aubry M, Cantu R, Dvorak J, Graf-Baumann T, Johnston K, Kelly J, et al. Summary and agreement statement of the First International Conference on Concussion in Sport, Vienna 2001. Recommendations for the improvement of safety and health of athletes who may suffer concussive injuries. British journal of sports medicine. 2002 Feb;36(1):6-10.

2. McCrory P, Johnston K, Meeuwisse W, Aubry M, Cantu R, Dvorak J, et al. Summary and agreement statement of the 2nd International Conference on Concussion in Sport, Prague 2004. British journal of sports medicine. 2005 Apr;39(4):196-204.

3. Maddocks D, Dicker G. An objective measure of recovery from concussion in Australian rules footballers. Sport Health. 1989;7(Supplement):6-7.

4. Maddocks DL, Dicker GD, Saling MM. The assessment of orientation following concussion in athletes. Clin J Sport Med. 1995;5(1):32-5.

5. McCrea M. Standardized mental status assessment of sports concussion. Clin J Sport Med. 2001 Jul;11(3):176-81.

6. McCrea M, Kelly J, Randolph C, Kluge J, Bartolic E, Finn G, et al. Standardised assessment of concussion (SAC): On site mental status evaluation of the athlete. J Head Trauma Rehab. 1998;13:27-36.

7. McCrea M, Randolph C, Kelly J. The Standardized Assessment of Concussion (SAC): Manual for Administration, Scoring and Interpretation. 2nd ed. Waukesha, WI 2000.

8. McCrea M, Kelly JP, Kluge J, Ackley B, Randolph C. Standardized assessment of concussion in football players. Neurology. 1997 Mar;48(3):5868.

9. Chen J, Johnston K, Collie A, McCrory P, Ptito A. A validation of the Post Concussion Symptom Scale in the assessment of complex concussion using cognitive testing and functional MRI. J Neurol Neurosurg Psych. 2007:in press.

10. Chen J, Johnston K, Frey S, Petrides M, Worsley K, Ptito A. Functional abnormalities in symptomatic concussed athletes: an fMRI study. Neuroimage 2004;22(1):68-82

11. Chen JK, Johnston KM, Collie A, McCrory P, Ptito A. (14) Association between symptom severity, cogsport tests results, and functional MRI activation in symptomatic concussed athletes. Clin J Sport Med. 2004 Nov 2004;14(6):379.

12. Chen JK, Johnston KM, Collie A, McCrory P, Ptito A. Behavioural and Functional Imaging Outcomes in Symptomatic Concussed Athletes Measured with Cogsport and Functional MRI. BJ Sport Med. 2004 Oct 2004;38(5):659.

13. Ptito A, Chen JK, Johnston KM. Contributions of functional magnetic resonance imaging (fMRI) to sport concussion evaluation. NeuroRehabilitation. 2007;22(3):217-27.

14. Guskiewicz K. Postural stability assessment following concussion. Clin J Sport Med. 2001;11:182-90.

15. Guskiewicz KM. Assessment of postural stability following sport-related concussion. Current sports medicine reports. 2003 Feb;2(1):24-30.

16. Guskiewicz KM, Ross SE, Marshall SW. Postural Stability and Neuropsychological Deficits After Concussion in Collegiate Athletes. Journal of athletic training. 2001 Sep;36(3):263-73.

17. Cavanaugh JT, Guskiewicz KM, Giuliani C, Marshall S, Mercer V, Stergiou N. Detecting altered postural control after cerebral concussion in athletes with normal postural stability. British journal of sports medicine. 2005 Nov;39(11):805-11.

18. Cavanaugh JT, Guskiewicz KM, Giuliani C, Marshall S, Mercer VS, Stergiou N. Recovery of postural control after cerebral concussion: new insights using approximate entropy. Journal of athletic training. $2006 \mathrm{Jul}-$ Sep;41(3):305-13.

19. Cavanaugh JT, Guskiewicz KM, Stergiou N. A nonlinear dynamic approach for evaluating postural control: new directions for the management of sport-related cerebral concussion. Sports medicine (Auckland, NZ. $2005 ; 35(11): 935-50$ 
20. Fox ZG, Mihalik JP, Blackburn JT, Battaglini CL, Guskiewicz KM. Return of postural control to baseline after anaerobic and aerobic exercise protocols. Journal of athletic training. 2008 Sep-Oct;43(5):456-63.

21. Collie A, Darby D, Maruff P. Computerised cognitive assessment of athletes with sports related head injury. British journal of sports medicine. 2001 Oct;35(5):297-302.

22. Collie A, Maruff P. Computerised neuropsychological testing. British journal of sports medicine. 2003 Feb;37(1):2-3

23. Collie A, Maruff P, McStephen M, Darby DG. Psychometric issues associated with computerised neuropsychological assessment of concussed athletes. British journal of sports medicine. 2003 Dec;37(6):556-9.

24. Collins MW, Grindel SH, Lovell MR, Dede DE, Moser DJ, Phalin BR, et al. Relationship between concussion and neuropsychological performance in college football players [see comments]. Jama. 1999;282(10):964-70.

25. Lovell MR. The relevance of neuropsychologic testing for sports-related head injuries. Current sports medicine reports. 2002 Feb;1(1):7-11.

26. Lovell MR, Collins MW. Neuropsychological assessment of the college football player. The Journal of head trauma rehabilitation. 1998 Apr;13(2):9-26.

27. Bleiberg J, Cernich AN, Cameron K, Sun W, Peck K, Ecklund PJ, et al. Duration of cognitive impairment after sports concussion. Neurosurgery. 2004 May;54(5):1073-78; discussion 8-80.

28. Bleiberg J, Warden D. Duration of cognitive impairment after sports concussion. Neurosurgery. 2005 May;56(5):E1166.

29. Broglio SP, Macciocchi SN, Ferrara MS. Neurocognitive performance of concussed athletes when symptom free. Journal of athletic training. 2007 Oct-Dec;42(4):504-8.

30. Broglio SP, Macciocchi SN, Ferrara MS. Sensitivity of the concussion assessment battery. Neurosurgery. 2007 Jun;60(6):1050-7; discussion 7-8.

31. Gioia G, Janusz J, Gilstein K, Iverson GL. Neueopsychological management of consussion in children and adolescents: effects of age and gender on ImPact. (abstract). Br J Sp Med. 2004;38:657.

32. McCrory P, Collie A, Anderson V, Davis G. Can we manage sport related concussion in children the same as in adults? British journal of sports medicine. 2004 Oct;38(5):516-9.

33. Kristman VL, Tator $\mathrm{CH}$, Kreiger N, Richards D, Mainwaring L, Jaglal S, et al. Does the apolipoprotein epsilon 4 allele predispose varsity athletes to concussion? A prospective cohort study. Clin J Sport Med. 2008 Jul;18(4):322-8.

34. Terrell TR, Bostick RM, Abramson R, Xie D, Barfield W, Cantu R, et al. APOE, APOE promoter, and Tau genotypes and risk for concussion in college athletes. Clin J Sport Med. 2008 Jan;18(1):10-7.

35. Vagnozzi R, Tavazzi B, Signoretti S, Amorini AM, Belli A, Cimatti M, et al. Temporal window of metabolic brain vulnerability to concussions: mitochondrial-related impairment--part I. Neurosurgery. 2007 Aug;61(2):37988; discussion 88-9.

36. Hang CH, Chen G, Shi JX, Zhang X, Li JS. Cortical expression of nuclear factor kappaB after human brain contusion. Brain research. 2006 Sep 13;1109(1):14-21.

37. Peng RY, Gao YB, Xiao XY, Wang DW, Chen HY, Wu XH, et al. [Study on the expressions of basic fibroblast growth factor and nervous growth factor genes in rat cerebral concussion]. Zhongguo Wei Zhong Bing Ji Jiu Yi Xue. 2003 Apr;15(4):213-6.

38. Yunoki M, Kawauchi M, Ukita N, Noguchi Y, Nishio S, Ono Y, et al. Effects of lecithinized SOD on sequential change in SOD activity after cerebral contusion in rats. Acta Neurochir Suppl. 1998;71:142-5.

39. Hinkle DA, Baldwin SA, Scheff SW, Wise PM. GFAP and S100beta expression in the cortex and hippocampus in response to mild cortical contusion. Journal of neurotrauma. 1997 Oct;14(10):729-38.

40. Holmin S, Schalling M, Hojeberg B, Nordqvist AC, Skeftruna AK, Mathiesen T. Delayed cytokine expression in rat brain following experimental contusion. Journal of neurosurgery. 1997 Mar;86(3):493-504.

41. Sandberg Nordqvist AC, von Holst $\mathrm{H}$, Holmin S, Sara VR, Bellander BM, Schalling M. Increase of insulin-like growth factor (IGF)-1, IGF binding protein-2 and -4 mRNAs following cerebral contusion. Brain Res Mol Brain Res. 1996 Jun;38(2):285-93

42. Fukuhara $\mathrm{T}$, Nishio $\mathrm{S}$, Ono $\mathrm{Y}$, Kawauchi M, Asari S, Ohmoto T. Induction of $\mathrm{Cu}, \mathrm{Zn}$-superoxide dismutase after cortical contusion injury during hypothermia. Brain research. 1994 Sep 19;657(1-2):333-6.

43. Boutin D, Lassonde M, Robert M, Vanassing P, Ellemberg D. Neurophysiological assessment prior to and following sports-related concussion during childhood: a case study. Neurocase. 2008;14(3):239-48.

44. De Beaumont L, Brisson B, Lassonde M, Jolicoeur P. Long-term electrophysiological changes in athletes with a history of multiple concussions. Brain Inj. 2007 Jun;21(6):631-44
45. De Beaumont L, Lassonde $M$, Leclerc $S$, Theoret $H$. Long-term and cumulative effects of sports concussion on motor cortex inhibition. Neurosurgery. 2007 Aug;61(2):329-36; discussion 36-7.

46. Gaetz M, Weinberg $H$. Electrophysiological indices of persistent postconcussion symptoms. Brain Inj. 2000 Sep;14(9):815-32.

47. Gosselin N, Theriault M, Leclerc S, Montplaisir J, Lassonde M. Neurophysiological anomalies in symptomatic and asymptomatic concussed athletes. Neurosurgery. 2006 Jun;58(6):1151-61; discussion -61.

48. Lavoie ME, Dupuis F, Johnston KM, Leclerc S, Lassonde M. Visual p300 effects beyond symptoms in concussed college athletes. J Clin Exp Neuropsychol. 2004 Feb;26(1):55-73.

49. Rousseff RT, Tzvetanov P, Atanassova PA, Volkov I, Hristova I. Correlation between cognitive $\mathrm{P} 300$ changes and the grade of closed head injury. Electromyogr Clin Neurophysiol. 2006 Sep;46(5):275-7.

50. Begaz T, Kyriacou DN, Segal J, Bazarian JJ. Serum biochemical markers for post-concussion syndrome in patients with mild traumatic brain injury. Journal of neurotrauma. 2006 Aug;23(8):1201-10.

51. de Boussard CN, Lundin A, Karlstedt D, Edman G, Bartfai A, Borg J. S100 and cognitive impairment after mild traumatic brain injury. J Rehabil Med. 2005 Jan;37(1):53-7.

52. Lima DP, Simao Filho C, Abib Sde C, de Figueiredo LF. Quality of life and neuropsychological changes in mild head trauma. Late analysis and correlation with S100B protein and cranial CT scan performed at hospital admission. Injury. 2008 May;39(5):604-11.

53. Ma M, Lindsell CJ, Rosenberry CM, Shaw GJ, Zemlan FP. Serum cleaved tau does not predict postconcussion syndrome after mild traumatic brain injury. Am J Emerg Med. 2008 Sep;26(7):763-8.

54. Stalnacke BM, Tegner Y, Sojka P. Playing ice hockey and basketball increases serum levels of S-100B in elite players: a pilot study. Clin J Sport Med. 2003 Sep;13(5):292-302

55. Stalnacke BM, Tegner $Y$, Sojka P. Playing soccer increases serum concentrations of the biochemical markers of brain damage S-100B and neuron-specific enolase in elite players: a pilot study. Brain Inj. 2004 Sep;18(9):899-909.

56. Townend $\mathrm{W}$, Ingebrigtsen $\mathrm{T}$. Head injury outcome prediction: a role for protein S-100B? Injury. 2006 Dec;37(12):1098-108.

57. Johnston K, Bloom G, Ramsay J, Kissick J, Montgomery D, Foley D, et al. Current Concepts in Concussion Rehabilitation. Current sports medicine reports. 2004;3:316-23.

58. Guskiewicz KM, Bruce SL, Cantu RC, Ferrara MS, Kelly JP, McCrea $\mathrm{M}$, et al. National Athletic Trainers' Association Position Statement: Management of Sport-Related Concussion. Journal of athletic training. 2004 Sep;39(3):280-97.

59. Herring S, Bergfeld J, Boland A, Boyajian-O'Neill L, Cantu R, Hershman $\mathrm{E}$, et al. Concussion (mild traumatic brain injury) and the team physician: a consensus statement. Medicine and science in sports and exercise. 2006 Feb;38(2):395-9.

60. Kelly JP, Rosenberg JH. The development of guidelines for the management of concussion in sports. The Journal of head trauma rehabilitation. 1998 Apr;13(2):53-65

61. Pellman EJ, Viano DC, Casson IR, Arfken C, Feuer H. Concussion in professional football: players returning to the same game--part 7. Neurosurgery. 2005;56(1):79-90; discussion -2.

62. Guskiewicz KM, McCrea M, Marshall SW, Cantu RC, Randolph C, Barr $W$, et al. Cumulative effects associated with recurrent concussion in collegiate football players. JAMA. 2003 November 19, 2003;290(19):254955 .

63. Lovell M, Collins M, Bradley J. Return to play following sports-related concussion. Clinics in sports medicine. 2004 Jul;23(3):421-41, ix.

64. Collins M, Field M, Lovell M, G I, Johnston K, Maroon J, et al. Relationship between postconcussion headache and neuropsychological test performance in high school athletes. The American journal of sports medicine. 2003;31:168-73.

65. Collins M, Grindel S, Lovell M, Dede D, Moser D, Phalin B, et al. Relationship between concussion and neuropsychological performance in college football players. J Am Med Assoc. 1999;282:964-70.

66. Collins MW, Lovell MR, Iverson GL, Cantu RC, Maroon JC, Field M. Cumulative effects of concussion in high school athletes. Neurosurgery. 2002 Nov;51(5):1175-9; discussion 80-1.

67. McCrea M, et al. Acute effects and recovery time following concussion in collegiate football players. JAMA. 2003;290:2556-63.

68. McCrea M, Hammeke T, Olsen G, Leo P, Guskiewicz K. Unreported concussion in high school football players: implications for prevention. Clin J Sport Med. 2004 Jan;14(1):13-7. 
69. Bloom G, Horton A, McCrory P, Johnston K. Sport psychology and concussion: new impacts to explore. British journal of sports medicine. 2004;38(5):519-21.

70. Bloom G, Horton A, McCrory P, Johnstone K. The role of interventional sports psychological techniques following concussion. British journal of sports medicine. 2004;38:519-21.

71. McCrory P. Should we treat concussion pharmacologically? The need for evidence based pharmacological treatment for the concussed athlete. British journal of sports medicine. 2002 Feb;36(1):3-5

72. McCrory P. Preparticipation assessment for head injury. Clin J Sport Med 2004 May;14(3):139-44.

73. Johnston KM, Lassonde M, Ptito A. A Contemporary Neurosurgical Approach to Sport-Related Head Injury: The McGill Concussion Protocol. Journal of The American College of Surgeons. 2001:515-24.

74. Delaney J, Lacroix V, Leclerc S, Johnston K. Concussions during the 1997 Canadian Football League Season. Clin J Sport Med. 2000;10:9-14.

75. Delaney J, Lacroix V, Leclerc S, Johnston K. Concussions among university football and soccer players. Clinical Journal of Sport Medicine. 2002;12(6):331-8

76. Gessel LM, Fields SK, Collins CL, Dick RW, Comstock RD. Concussions among United States high school and collegiate athletes. Journal of athletic training. 2007 Oct-Dec;42(4):495-503.

77. Dvorak J, Junge A, Fuller C, McCrory P. Medical issues in women's football. British journal of sports medicine. 2007 Aug;41 Suppl 1:i1.

78. Dvorak J, McCrory P, Kirkendall DT. Head injuries in the female football player: incidence, mechanisms, risk factors and management. British journal of sports medicine. 2007 Aug;41 Suppl 1:i44-6.

79. Jennett B, Bond M. Assessment of outcome after severe brain damage: a practical scale. Lancet. 1975;1:480-4

80. Leninger B, Gramling S, Farrell A, Kreutzer J, Peck E. Neuropsychological deficits in symptomatic minor head injury patients after concussion and mild concussion. J Neurol Neurosurg Psych. 1990;53:293-6.

81. Lovell M, Iverson G, Collins M, McKeag D, Maroon J. Does loss of consciousness predict neuropsychological decrements after concussion. Clin J Sp Med. 1999;9:193-9.

82. McCrea M, Kelly J, Randolph C, Cisler R, Berger L. Immediate neurocognitive effects of concussion. Neurosurgery. 2002;50(5):1032-42.

83. Cantu RC. Posttraumatic retrograde and anterograde amnesia: Pathophysiology and implications in grading and safe return to play. J Athletic Training. 2001;36((3)):244-8

84. Lovell MR, Collins MW, Iverson GL, Field M, Maroon JC, Cantu RC, et al. Recovery from mild concussion in high school atheltes. JNeurosurg. 2003 February 2003;98:296-301.

85. McCrory PR, Ariens T, Berkovic SF. The nature and duration of acute concussive symptoms in Australian football. Clin J Sport Med. 2000 Oct;10(4):235-8.

86. Yarnell P, Lynch S. The 'ding': amnestic state in football trauma. Neurology. 1973;23:196-7.

87. Yarnell PR, Lynch S. Retrograde memory immediately after concussion. Lancet. 1970;1(7652):863-4.

88. McCrory PR, Berkovic SF. Video analysis of acute motor and convulsive manifestations in sport-related concussion. Neurology. 2000 Apr 11;54(7):1488-91.

89. McCrory PR, Bladin PF, Berkovic SF. Retrospective study of concussive convulsions in elite Australian rules and rugby league footballers: phenomenology, aetiology, and outcome. BMJ (Clinical research ed. 1997 Jan 18;314(7075):171-4

90. Fleminger $\mathrm{S}$. Long-term psychiatric disorders after traumatic brain injury Eur J Anaesthesiol Suppl. 2008;42:123-30.

91. Chen JK, Johnston KM, Petrides M, Ptito A. Neural substrates of symptoms of depression following concussion in male athletes with persisting postconcussion symptoms. Arch Gen Psychiatry. 2008 Jan;65(1):81-9.

92. Bryant RA. Disentangling mild traumatic brain injury and stress reactions The New England journal of medicine. 2008 Jan 31;358(5):525-7.

93. Vanderploeg RD, Curtiss G, Luis CA, Salazar AM. Long-term morbidities following self-reported mild traumatic brain injury. J Clin Exp Neuropsychol. 2007 Aug;29(6):585-98.

94. Guskiewicz KM, Marshall SW, Bailes J, McCrea M, Harding HP, Jr., Matthews $\mathrm{A}$, et al. Recurrent concussion and risk of depression in retired professional football players. Medicine and science in sports and exercise. 2007 Jun;39(6):903-9.

95. Kashluba S, Casey JE, Paniak C. Evaluating the utility of ICD-10 diagnostic criteria for postconcussion syndrome following mild traumatic brain injury. J Int Neuropsychol Soc. 2006 Jan;12(1):111-8.
96. Iverson GL. Misdiagnosis of the persistent postconcussion syndrome in patients with depression. Arch Clin Neuropsychol. 2006 May;21(4):30310.

97. Chamelian L, Feinstein A. The effect of major depression on subjective and objective cognitive deficits in mild to moderate traumatic brain injury. The Journal of neuropsychiatry and clinical neurosciences. 2006 Winter;18(1):33-8.

98. Mooney G, Speed J, Sheppard S. Factors related to recovery after mild traumatic brain injury. Brain Inj. 2005 Nov;19(12):975-87.

99. Broshek DK, Freeman JR. Psychiatric and neuropsychological issues in sport medicine. Clinics in sports medicine. 2005 Jul;24(3):663-79, x.

100. Pellman EJ. Background on the National Football League's research on concussion in professional football. Neurosurgery. 2003 Oct;53(4):797-

101. Purcell L, Carson J. Sport-related concussion in pediatric athletes. Clin Pediatr (Phila). 2008 Mar;47(2):106-13

102. Lee LK. Controversies in the sequelae of pediatric mild traumatic brain injury. Pediatric emergency care. 2007 Aug;23(8):580-3; quiz 4-6.

103. Schnadower D, Vazquez H, Lee J, Dayan P, Roskind CG. Controversies in the evaluation and management of minor blunt head trauma in children. Current opinion in pediatrics. 2007 Jun;19(3):258-64.

104. Wozniak JR, Krach L, Ward E, Mueller BA, Muetzel R, Schnoebelen S, et al. Neurocognitive and neuroimaging correlates of pediatric traumatic brain injury: a diffusion tensor imaging (DTI) study. Arch Clin Neuropsychol. 2007 Jun;22(5):555-68

105. Hayden MG, Jandial R, Duenas HA, Mahajan R, Levy M. Pediatric concussions in sports; a simple and rapid assessment tool for concussive injury in children and adults. Childs Nerv Syst. 2007 Apr;23(4):431-5.

106. Lee MA. Adolescent concussions--management recommendations: a practical approach. Connecticut medicine. 2006 Jun-Jul;70(6):377-80.

107. Kirkwood MW, Yeates KO, Wilson PE. Pediatric sport-related concussion: a review of the clinical management of an oft-neglected population. Pediatrics. 2006 Apr;117(4):1359-71.

108. Guskiewicz KM, Marshall SW, Bailes J, McCrea M, Cantu RC, Randolph $\mathrm{C}$, et al. Association between recurrent concussion and late-life cognitive impairment in retired professional football players. Neurosurgery. 2005 Oct;57(4):719-26; discussion -26.

109. Nandoe RD, Scheltens P, Eikelenboom P. Head trauma and Alzheimer's disease. J Alzheimers Dis. 2002 Aug;4(4):303-8.

110. Stern MB. Head trauma as a risk factor for Parkinson's disease. Mov Disord. 1991;6(2):95-7.

111. Omalu BI, DeKosky ST, Hamilton RL, Minster RL, Kamboh MI, Shakir AM, et al. Chronic traumatic encephalopathy in a national football league player: part II. Neurosurgery. 2006 Nov;59(5):1086-92; discussion 92-3.

112. Omalu BI, DeKosky ST, Minster RL, Kamboh MI, Hamilton RL, Wecht CH. Chronic traumatic encephalopathy in a National Football League player. Neurosurgery. 2005 Jul;57(1):128-34; discussion -34.

113. Hagel BE, Pless IB, Goulet C, Platt RW, Robitaille Y. Effectiveness of helmets in skiers and snowboarders: case-control and case crossover study. BMJ (Clinical research ed. 2005 Feb 5;330(7486):281.

114. McCrory $P$. The role of helmets in skiing and snowboarding. British journal of sports medicine. 2002 Oct;36(5):314

115. Mueller BA, Cummings P, Rivara FP, Brooks MA, Terasaki RD. Injuries of the head, face, and neck in relation to ski helmet use. Epidemiology. 2008 Mar; 19(2):270-6

116. Sulheim S, Holme I, Ekeland A, Bahr R. Helmet use and risk of head injuries in alpine skiers and snowboarders. Jama. 2006 Feb 22;295(8):91924.

117. Delaney JS, Al-Kashmiri A, Drummond R, Correa JA. The effect of protective headgear on head injuries and concussions in adolescent football (soccer) players. British journal of sports medicine. 2008 Feb;42(2):110-5; discussion 5.

118. Viano DC, Pellman EJ, Withnall C, Shewchenko N. Concussion in professional football: performance of newer helmets in reconstructed game impacts--Part 13. Neurosurgery. 2006 Sep;59(3):591-606; discussion 591-606.

119. Finch C, Braham R, Mclntosh A, McCrory P, Wolfe R. Should football players wear custom fitted mouthguards? Results from a group randomised controlled trial. Inj Prev. 2005 Aug;11(4):242-6.

120. McIntosh A, McCrory P. The dynamics of concussive head impacts in rugby and Australian rules football. Medicine and science in sports and exercise. 2000:32:1980-5.

121. McIntosh A, McCrory P. Impact energy attenuation performance of football headgear. British journal of sports medicine. 2000;34:337-42. 
122. Mclntosh A, McCrory P. Effectiveness of headgear in a pilot study of under 15 rugby union football. British journal of sports medicine. 2001;35:16770.

123. McIntosh A, McCrory P, FInch C, Best J, Chalmers D. Rugby Headgear Study Report. School of Safety Science, The University of New South Wales, Sydney, Australia, May 2005.

124. Finch C, Newstead S, Cameron M, Vulcan A. Head injury reductions in Victoria two years after the introduction of mandatory bicycle helmet use. Melbourne: Monash University Accident Research Centre, July 1993. Report No.: 51.

125. Curnow WJ. Bicycle helmets and public health in Australia. Health Promot J Austr. 2008 Apr;19(1):10-5.

126. Hewson PJ. Cycle helmets and road casualties in the UK. Traffic Inj Prev. 2005 Jun;6(2):127-34

127. Davidson JA. Epidemiology and outcome of bicycle injuries presenting to an emergency department in the United Kingdom. Eur J Emerg Med. 2005 Feb;12(1):24-9.

128. Hansen KS, Engesaeter LB, Viste A. Protective effect of different types of bicycle helmets. Traffic Inj Prev. 2003 Dec;4(4):285-90.

129. Andersen T, Arnason A, Engebretsen L, Bahr R. Mechanism of head injuries in elite football. British journal of sports medicine. 2004;38:690-6.

130. Hagel B, Meewisse W. Editorial: Risk Compensation: A "Side Effect" of Sport Injury Prevention? Clin J Sp Med. 2004 July 2004;14(4):193-6.

131. Finch $C$, Mcintosh AS, McCrory $P$, Zazryn T. A pilot study of the attitudes of Australian Rules footballers towards protective headgear. Journal of Science and Medicine in Sport. 2003;6(4):505-11

132. Finch CF, McIntosh AS, McCrory P. What do under 15 year old schoolboy rugby union players think about protective headgear? British journal of sports medicine. $2001 \mathrm{Apr} ; 35(2): 89-94$

133. Finch CF, Mclntosh AS, McCrory P, Zazryn T. A pilot study of the attitudes of Australian Rules footballers towards protective headgear. J Sci Med Sport. 2003 Dec;6(4):505-11

134. Reece RM, Sege R. Childhood head injuries: accidental or inflicted? Arch Pediatr Adolesc Med. 2000 Jan;154(1):11-5.

135. Shaw NH. Bodychecking in hockey. CMAJ. 2004 Jan 6;170(1):15-6; author reply 6,8 .

136. Denke NJ. Brain injury in sports. J Emerg Nurs. 2008 Aug;34(4):363-4.

137. Gianotti S, Hume PA. Concussion sideline management intervention for rugby union leads to reduced concussion claims. NeuroRehabilitation. 2007;22(3):181-9

138. Guilmette TJ, Malia LA, McQuiggan MD. Concussion understanding and management among New England high school football coaches. Brain Inj. 2007 Sep;21(10):1039-47.

139. Hootman JM, Dick R, Agel J. Epidemiology of collegiate injuries for 15 sports: summary and recommendations for injury prevention initiatives. Journal of athletic training. 2007 Apr-Jun;42(2):311-9.

140. Valovich McLeod TC, Schwartz C, Bay RC. Sport-related concussion misunderstandings among youth coaches. Clin J Sport Med. 2007 Mar;17(2):140-2.

141. Sye G, Sullivan SJ, McCrory P. High school rugby players' understanding of concussion and return to play guidelines. British journal of sports medicine. 2006 Dec;40(12):1003-5.

142. Theye F, Mueller KA. "Heads up": concussions in high school sports. Clin Med Res. 2004 Aug;2(3):165-71.

143. Kashluba S, Paniak C, Blake T, Reynolds S, Toller-Lobe G, Nagy J. A longitudinal, controlled study of patient complaints following treated mild traumatic brain injury. Arch Clin Neuropsychol. 2004 Sep;19(6):805-16.

144. Gabbe B, Finch CF, Wajswelner H, Bennell K. Does community-level Australian football support injury prevention research? J Sci Med Sport. 2003 Jun;6(2):231-6.

145. Kaut KP, DePompei R, Kerr J, Congeni J. Reports of head injury and symptom knowledge among college athletes: implications for assessment and educational intervention. Clin J Sport Med. 2003 Jul;13(4):213-21.

146. Davidhizar R, Cramer C. "The best thing about the hospitalization was that the nurses kept me well informed" Issues and strategies of client education. Accid Emerg Nurs. 2002 Jul;10(3):149-54

147. McCrory P. What advice should we give to athletes postconcussion? British journal of sports medicine. 2002 Oct;36(5):316-8.

148. Bazarian JJ, Veenema T, Brayer AF, Lee E. Knowledge of concussion guidelines among practitioners caring for children. Clin Pediatr (Phila). 2001 Apr;40(4):207-12.

\section{APPENDIX*}

\section{Pocket SCAT2}

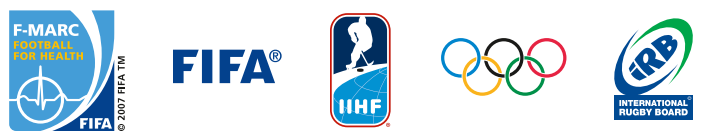

Concussion should be suspected in the presence of any one or more of the following: symptoms (such as headache), or physical signs (such as unsteadiness), or impaired brain function (e.g. confusion) or abnormal behaviour.

\section{Symptoms}

Presence of any of the following signs \& symptoms may suggest a concussion.

- Loss of consciousness

- Seizure or convulsion

- Feeling slowed down

- Amnesia

- Headache

- "Pressure in head"

- Neck Pain

- Nausea or vomiting

- Dizziness

- Blurred vision

- Balance problems

- Sensitivity to light

- Feeling like "in a fog"

- "Don't feel right"

- Difficulty concentrating

- Difficulty remembering

- Fatigue or low energy

- Confusion

- Drowsiness

- More emotional

- Irritability

- Sadness

- Sensitivity to noise

- Nervous or anxious

\section{Memory function}

Failure to answer all questions correctly may suggest a concussion.

"At what venue are we at today?"

"Which half is it now?"

"Who scored last in this game?"

"What team did you play last week/game?"

"Did your team win the last game?"

\section{Balance testing}

Instructions for tandem stance

"Now stand heel-to-toe with your non-dominant foot in back. Your weight should be evenly distributed across both feet. You should try to maintain stability for 20 seconds with your hands on your hips and your eyes closed. I will be counting the number of times you move out of this position. If you stumble out of this position, open your eyes and return to the start position and continue balancing. I will start timing when you are set and have closed your eyes."

Observe the athlete for 20 seconds. If they make more than 5 errors (such as lift their hands off their hips; open their eyes; lift their forefoot or heel; step, stumble, or fall; or remain out of the start position for more that 5 seconds) then this may suggest a concussion.

Any athlete with a suspected concussion should be IMMEDIATELY REMOVED FROM PLAY, urgently assessed medically, should not be left alone and should not drive a motor vehicle.

*The appendix is available as a separate document on the website www.sajsm.org.za 


\section{SCAT2 \\ 2) FIFA \& \\ (2)}

Sport Concussion Assessment Tool 2

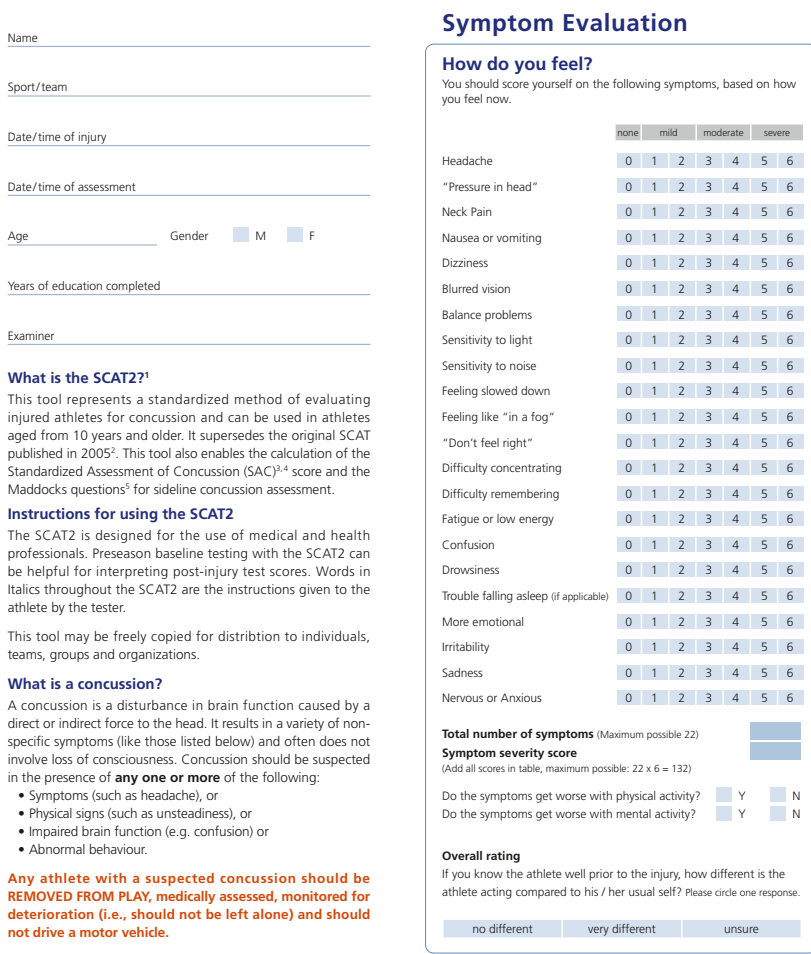

SCAT2 SPORT CONCUSSION ASSESMENT TOOL 2 P PAGE

\section{Cognitive \& Physical Evaluation}

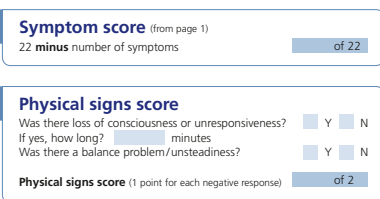

Glasgow coma scale (GCS)

Best eye response (E)
No eye opening

Eye opening in response to pain
Eye opening to speech

Best verbal response (v)

Best verbal response (V)
No verbal response

Incomprehensible sound
Inappropriate words
Confused

Best motor response (M)

Extension to pain
Abnormal flexion to pain

Flexion/Withdrawal to
Localizes to pain

Localizes to pain
Obeys commands

Glasgow Coma score $(E+V+m)$

Sideline Assessment - Maddocks Scor "I am going to ask you a fen

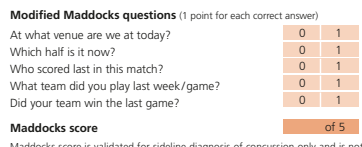

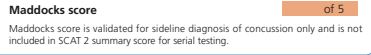

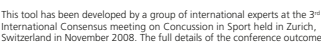

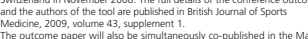

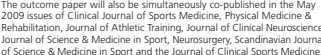

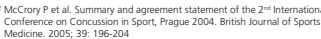

Cognitive assessment

Standardized Assessment of Concussion (SAC)

What month is it?
What is the date tod

What is the day of the week?

What year i i it?

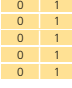

Orientation score

of 5

Immediate memory
"I Im going to test your memory. I will read you a list of words
and when I Im done, repeat back as many words as you can

Trials 283 :
"I gar going to repeat the same list again. Repeat back as many
words as you can remember in any order, even if you said the

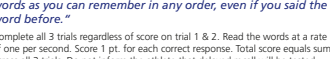

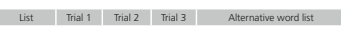

$\begin{array}{lllllllll}\text { eibow } & 0 & 1 & 0 & 1 & 0 & 1 & \text { candle } \\ \text { apple } & 0 & 1 & 0 & 1 & 0 & 1 & \text { paby finger } \\ \text { monkey penny }\end{array}$

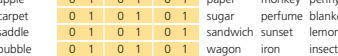

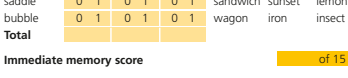

Concentration
Digits Backward:
"l am going to re

Tam going to read you a string of numbers and when l am don
you repeat them back to me backwards, in reverse order of how

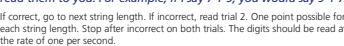

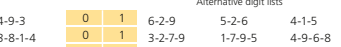

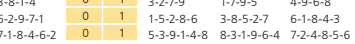

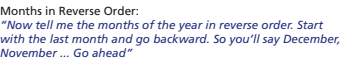

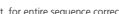

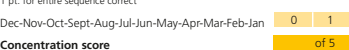

Concentration score

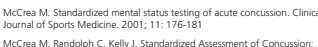

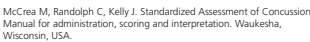

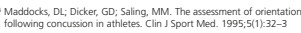

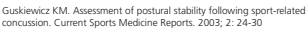

Balance examination

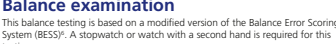

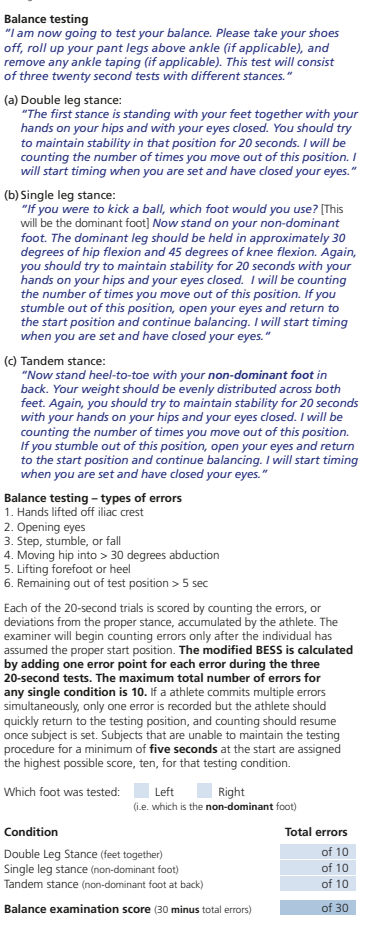

Coordination examination

Upper limb coordination
Finger-to-nose (FTN) task: start signal, I would like you to perform five successive finger to
nose repetititins using your index finger to touch the tip of the cly and as accurately as possible "

was tested: Left Righ

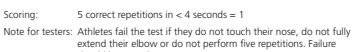

Coordination score

Cognitive assessment

Cognitive assessment

Selayed recall
Dessessment of Concussion (SAC)

Delayed recall
aDo you remer that list of words I read a few times earlier?
Tell me as many words from the list as you can remember in any

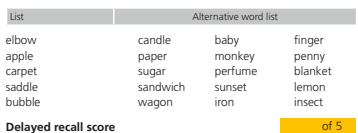

Overall score

Test domain

Symptom score
Physical signs score

Physical signs score
Glasgow Coma 5 core $(E+V+M)$

Balance examination sco

Coordination scor
Subtotal

Orientation score

Immeciate memory se

Delayed recall scor
SAC subtotal

of 5

Definitive normative data for a SCAT2 "Cut-off" score is not
available at this time and will be develeped in prospective studies

Separately in concussion management. The secring gystem also tokes
on particular clinical significance during serial assessment where on particular clinical significance during serial assessment where
it can eu used to document either a decline or an improvement
neuroulogical tunctioning

Scoring data from the SCAT2 or SAC should not be used as a stand alone method to diagnose concussion
neasure recovery or make decisions about an athlete's

\section{Athlete Information}

Signs to watch for

Return to play

Problems could arise over tre first $24-48$ hours. You should not be left
alone and must go to a hospital at once if you:

政

- Can't recognize people or places
Have repeated vomiting

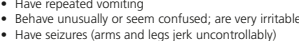

- Have weak or numb arms or legs

Remember, it is better to be safe.
Consult your doctor a f

Athletes should not be returned to play the same day of injury.
When returning athletes to play, they should follow a stepwise

symptom-limited program, with stages of progression. For examp

1. rest untili asymptomatic (physical and mental
2. light aerobic exercise (e.g. stationary cycle)
3. sport-spocific exercise

4. non--contact training drills start liaht resistance training
5. full contact training after medical clearance

6. return to competition (game play)

There should be approximately 24 hours (or longer) for each stage
and the athlete should return to stage 1 if symptoms recur. Resistance training should only be addded in the later stages.
Medical clearance should be given before return to play.

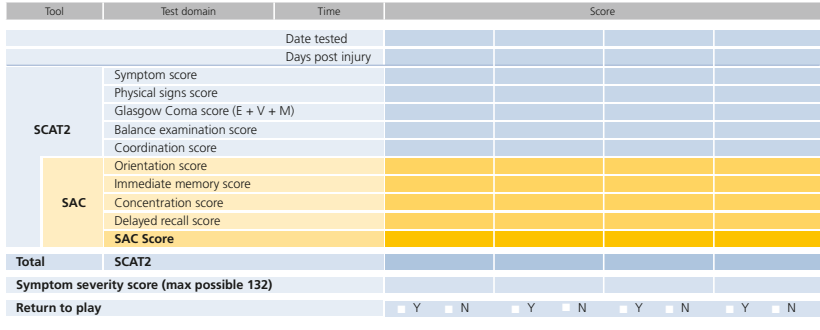

Additional comments

Concussion injury advice (To be given to concussed athlete)

This patient has received an injury to the head. A careful medical examination has been carried out and no sign of any serious complications has been found. It is expected
that recovery will be rapid, but the patient will need monitoring for a further period by a responsible adult. Your
treating physician will provide guidance as to this timeframe.

If you notice any change in behaviour, vomiting,

dizziness, worsening headache, double vision or

excessive drowsiness, please telephone the clinic

or the nearest
immediately.

Other important points:

$\because$ No alcohol

: No sleeping tables

aspirin or anti-inflammator for headache. Do not use

: aspirin or anti-inflammatory medication
Do not drive until medically cleared
Do not train or play sport until medically cleared

Clinic phone number
Date/time of injury

Date/time of medical review

Treating physiciar 